\title{
AS INCIDÊNCIAS ÉTICAS SUBENTENDIDAS/ENTRELIDAS NOS "ARTigos téCNicos" de Sigmund Freud ${ }^{\star}$
}

\author{
Júlio Eduardo de Castro $\star$ \\ Marcela Herthel de Oliveira ${ }^{\star \star}$
}

\begin{abstract}
RESUMO
Inicialmente, perguntamo-nos se é coerente, ética e doutrinariamente, chamar de técnica a prática psicanalitica? Daí investigamos se há, principalmente nos chamados "artigos técnicos", evidências ou ao menos indícios de que o tratamento criado por Freud esteja fundado em uma ética própria à psicanálise, não sendo possível reduzi-lo ao mero manejo de uma técnica. Sustentado no que foi sua "auto-análise", na teoria e na metodologia dai decorrentes, Freud deu mostras de que, na direção do tratamento, não há condução do sujeito, que o lugar/posição/ função do analista não é o de mestre e, acima de tudo, que a psicanálise não deve servir a nenhum ideal do eu ou da cultura. $O$ artigo pretende demonstrar como é possivel inferir, do texto freudiano principalmente a partir da leitura feita por Lacan uma ética voltada para o desejo. Por decorrência, este artigo evidencia a consistência da teoria freudiana, nitidamente nas dimensões ética e clínica.
\end{abstract}

Palavras-chave: ética da psicanálise; desejo; artigos freudianos sobre a técnica; direção do tratamento; desejo do psicanalista.

\section{The ETHICAL INCIDENCES PRESENTS IN FreUd'S "TECHNICAL ARTICLES"}

\begin{abstract}
At the beginning, we ask if it is coherent, ethically and doctrinally, to call the psychoanalysis' practice a technique. Then, we investigate if there are, especially on the so called "technical papers", evidences or at least clues that Freud's treatment is based in a self-ethical psychoanalysis, not being possible to reduce it to the simple handlings of a technique. Based on what was his "auto-analysis", on the following theory and methodology, Freud seemed to show that, in

^ Bolsa de iniciação científica (PIBIC) da Fundação de Apoio à Pesquisa do Estado de Minas Gerais (FAPEMIG)

* Psicanalista e pesquisador do Núcleo de Pesquisa e Extensão em Psicanálise - NUPEP da Universidade Federal de São João del-Rei - UFSJ, doutor em Teoria Psicanalítica pela Universidade Federal do Rio de Janeiro - UFRJ). Endereço: Praça Dom Helvécio, 74. Bairro das Fábricas - São João del-Rei - MG Campus Dom Bosco - Sala 1.25. CEP: 36.301-160. E-mail: julioecastro@mgconecta.com.br

$\star \star \star$ Bolsista de Iniciação Científica do PIBIC- FAPEMIG), graduada em Psicologia pela Universidade Federal de São João del-Rei - UFSJ).

E-mail: marcelaherthel@hotmail.com
\end{abstract}


treatment, there is no carriage of the subject, and that the place/position/function of the psychoanalyst isn't the position of a master and, above all, psychoanalysis shouldn't serve no ideals of the proper "self", or either cultural. This paper has the intention to demonstrate how it's possible to infer, in Freud's texts, an ethic about desire. As arising, this paper elucidates Freud's theory firmness, especially in the ethical and clinical dimensions.

Keywords: ethics on psychoanalysis; desire; freudian articles about technique; directions of treatment; the psychoanalysts'desire.

\section{1- INTRODUÇÃo}

O horizonte sobre o qual este estudo teórico realizou-se diz respeito a um recorte feito sobre a obra de Sigmund Freud com base na classificação - feita por James Strachey (1969-1980[1966]), editor inglês da Edição Standard Brasileira das Obras Psicológicas Completas de Sigmund Freud (1969-1980), de uma série de "Artigos sobre técnica" (FREUD, 1911-1915[1914]).

Segundo Strachey (1969-1980 [1966]), Freud nunca deixou de insistir que o domínio apropriado desse assunto, o método psicanalítico, somente poderia ser adquirido pela experiência clínica e não tanto pelos livros. Freud apontava para a importância da experiência clínica com pacientes, sem dúvida, mas, acima e antes de tudo, para a experiência clínica derivada da própria análise do psicanalista. Essa foi sendo constituída cada vez mais intensamente no decorrer de sua obra como uma necessidade fundamental na formação do psicanalista.

De início, detectamos, nos textos freudianos em foco, que a escolha feita por Strachey (1969-1980[1966]) da palavra “técnica”, no mínimo, contribuía para um mal-entendido elementar: tratar a prática psicanalítica como um saber-fazer capaz de transmissão em forma de manual e de instruções técnicas. Além disso, a expressão "técnica psicanalítica" dava margem à desconsideração da dimensão ética que permeia a formação e o agir do psicanalista, dimensão essa nomeada por Lacan de "ética do desejo".

A relativa escassez de trabalhos de Freud sobre o método psicanalítico, bem como sua hesitação e demora em produzi-los, sugere que havia, de sua parte, uma relutância em publicar esse tipo de material. De acordo com a introdução de Strachey (1969-1980[1966]) aos "Artigos sobre técnica", Freud temia a leitura e o uso indevidos a serem feitos principalmente pelos futuros pacientes. Por essa mesma razão Freud, em 1909, disse a Jones, seu biógrafo, que estava planejando "um pequeno memorando sobre máximas e normas de técnica" (STRACHEY, 1969-1980[1966], p. 111), que deveria ser distribuído privadamente apenas entre os seus mais chegados seguidores. Freud se preocupava, portanto, com possíveis efeitos a serem gerados pela publicação indiscriminada de seus artigos técnicos: 1- seu uso como resistência ao processo psicanalítico (feito pelos pacientes); 2 a leitura de que a prática da psicanálise é uma questão de seguir um manual de como bem-fazer (feita pelos leigos e analistas iniciantes). 
Portanto, essa preocupação de Freud, aliada à imprecisão e inadequação da palavra "técnica", quando referente à psicanálise, nos abriu um horizonte teórico de pesquisa: a dimensão ética da psicanálise. O uso da palavra "técnica" por Strachey (1969-1980[1966]) - como meio de agrupar alguns artigos freudianos diretamente ligados ao tratamento psicanalítico - intrigou-nos sobremaneira, principalmente por trazer a conotação, decorrente do tecnicismo inglês, de "conjunto de procedimentos materiais ligados a uma arte ou ciência" (FERREIRA, 2004, CD-ROM). Começamos por nos perguntar se estes artigos não mereceriam o título de "artigos sobre o método" ou simplesmente "metodologia psicanalítica" remetendo-nos aqui à etimologia: meta: "atrás, em seguida, através, além" e hodós: "caminho", ou mesmo de "artigos éticos". Tal pergunta inicial nos foi inspirada pela fórmula-lema lacaniana que afirma ser a ética da psicanálise a prática de sua teoria (LACAN, 1992).

Perguntamo-nos daí se, nesses textos freudianos, classificados por Strachey de "técnicos", haveria evidências, ou ao menos indícios, de que o tratamento está subordinado a uma ética própria à psicanálise, não sendo por isso mesmo possível reduzi-lo ao manuseio de uma técnica.

Essa dissonância entre, por um lado, "a ética da psicanálise" (sustentada na política da falta) e, por outro, a conotação de técnica (sustentada na presença material de recursos) nos permitiu formular um problema digno de investigação: Será coerente, doutrinária e eticamente, nomear a prática clínica psicanalítica proposta por Freud para a abordagem e tratamento das psiconeuroses de técnica?

\section{2- Metodologia}

Quanto ao modo de investigação adotado, utilizamos os recursos da pesquisa teórica, principalmente ao recortar a obra de Freud e o ensino de Lacan a partir de temas e textos pertinentes ao problema investigado. Leituras, releituras, fichamentos, resenhas e notas fizeram parte desse modo de investigação. Quanto ao modo de análise dos dados encontrados, nos servimos dos recursos da pesquisa qualitativa.

No trabalho de investigação, buscamos considerar não apenas o que estava explicitamente escrito no texto freudiano, mas também analisar o que poderia ser lido nas entrelinhas. Desse modo, buscamos a verdade de uma proposição em decorrência de sua ligação com outras já reconhecidas como verdadeiras. Por esse aspecto, ter inferido que os "escritos técnicos" são, antes de tudo, éticos, nos exigiu o exercício de ler Freud entre as palavras, entre as linhas e, principalmente, entre seus textos.

Nossa atenção e trabalho voltaram-se, portanto, para a extração de idéias que se encontravam subentendidas nas brechas que o texto freudiano fornecia. Para tal, algumas vezes nos foi necessário inferir aí, nas entrelinhas, algumas considerações referentes à ética da psicanálise. Este trabalho foi estendido aos Seminários 1 e 7 de Lacan (1985[1953-1954], 1988[1959-1960]), autor escolhido aqui como comentador privilegiado do texto freudiano. Os Seminários em questão se referiam, 
respectivamente, aos escritos técnicos de Freud (LACAN, 1985[1953-1954]) e à ética da psicanálise (LACAN, 1988[1959-1960]), tendo tido papel fundamental na construção do conceito de ética, segundo o ponto de vista psicanalítico.

Após a releitura exegética de vinte artigos freudianos (vide Referências) e desses dois Seminários de Lacan, cotejamos os textos entre si, colocando-os assim em diálogo. Como são textos, tanto os de Freud como os de Lacan, abertos ao sentido efeito do saber parcial e inacabado que tanto caracteriza a teoria psicanalítica -, foi possível nos servirmos de suas linhas e entrelinhas. Dessa maneira, foram examinadas não apenas as referências explícitas à ética da psicanálise, mas ainda consideradas as que se localizavam subterraneamente. Permitimo-nos ainda, durante a leitura e releitura dos textos, uma abertura à influência de um texto sobre outro que o toma como ponto de partida, e que gera a atualização do texto citado ao modo de intertextualidade. ${ }^{1}$ Esse movimento de leitura foi feito "entre os textos" (principalmente de Freud) e "entre os autores" (Freud e Lacan). De modo que ter trabalhado sobre textos de dois autores que focalizam um tema/objeto comum (o método psicanalítico) pondo-os, textos e autores, em diálogo nos permitiu fazer importantes considerações relativas aos seus pontos de semelhança, contradição e complementação. Daí foram extraídas concepções acerca da dimensão ética da psicanálise, todas elas voltadas para a necessária consideração ao desejo inconsciente por meio da determinação de seu objeto como / enquanto causa dos atos de um sujeito $(a \rightarrow \$)$.

\section{0- Desenvolvimento}

\section{1- Freud e a ética no tratamento}

A ética da psicanálise está originalmente subordinada à clinica psicanalítica, ou seja, ela é um derivado direto do tratamento psicanalítico. Freud (ano), ocupando-se do tratamento de sujeitos neuróticos, estabelece para eles uma regra, a regra fundamental, e apresenta como contrapartida para o psicanalista, a atenção flutuante e o princípio de abstinência. Sobre a primeira, o paciente "deve relatar tudo que sua auto-observação possa detectar, e impedir todas as objeções lógicas e afetivas que possam induzi-lo a fazer uma seleção dentre elas" (FREUD, 1969-1980[1912b], p.154). Na literatura psicanalítica, essa regra é conhecida como "associação livre" e, segundo Strachey (1969-1980[1966]), o termo "regra fundamental" foi empregado, pela primeira vez, no artigo de 1912, "A dinâmica da transferência" (FREUD, 1969-1980[1912a]), embora a idéia em si seja bem anterior, encontrando-se já expressa no capítulo II de "A interpretação dos sonhos" (FREUD, 1969-1980[1900]). Já a contrapartida do analista é simplesmente tudo escutar, sem se preocupar se está lembrando de alguma coisa, prestando, portanto, igual atenção a tudo que o paciente diz. No texto "Recomendações aos médicos que exercem a psicanálise", Freud (1969-1980[1912b]) afirma que as "regras técnicas" que apresenta podem ser facilmente resumidas em um preceito único. O analista deve "colocar-se em posição de fazer uso de tudo que lhe for dito para fins de interpretação e identificar o material inconsciente oculto sem substituir sua própria censura pela seleção de que o paciente abriu mão" (FREUD, 1969- 
1980[1912b], p. 154). Portanto, o "tudo dizer", do lado do analisante, implicava o "tudo escutar", do lado do analista, posição esta que lhe exigia ainda suportar frustrar as demandas transferenciais do sujeito, abster-se de atender a seus pedidos.

O tratamento deve ser levado a cabo na abstinência. Com isso não quero significar apenas a abstinência física, nem a privação de tudo o que a paciente deseja, pois talvez nenhuma pessoa enferma pudesse suportar isto Fixarei como princípio fundamental que se deve permitir que a necessidade e o anseio da paciente nela persistam, a fim de poderem servir de forças que a incentivem a trabalhar e efetuar mudanças e que devemos cuidar de apaziguar estas forças por meio de substitutivos (FREUD, 1969-1980[1915], p. 214).

Outro objetivo do princípio de abstinência era manter as associações do paciente preservadas das interferências e influências subjetivas do psicanalista, de sua pessoa. A este respeito, Freud ressalta que qualquer psicanalista que quiser estar em posição de agir assim, ou seja, contra o movimento do recalcamento, deve, ele próprio, ter se submetido à experiência psicanalítica e aí ficado ciente dos próprios complexos que, quando não reconhecidos e elaborados, podem interferir e comprometer sua escuta e seu agir sobre o que o paciente diz.

É possível ainda acrescentar que assim como o sujeito em análise deve falar tudo que lhe vier à mente, sem se guiar por nenhum tipo de censura - o psicanalista deve estar pronto a escutá-lo com a "atenção flutuante", a ouvi-lo sem censura ou julgamento, sem se deixar guiar por um ponto de vista moralizador ou por qualquer ideal e, principalmente, sem tentar conduzir o sujeito na direção de seus próprios ideais.

Sobre a expressão "neutralidade benevolente" do psicanalista, expressão essa utilizada algumas vezes por Freud para se referir à conduta clínica do psicanalista, a entendemos como sendo, antes de tudo, uma evidência de sua preocupação com o campo ético, principalmente naquilo que dissesse respeito ao uso e ao emprego do método psicanalítico. Segundo nossa leitura, a expressão freudiana "neutralidade benevolente" - marcada pela combinação do ideal da ciência com a idéia do "bem supremo" aristotélico - incide sobre esse campo ético, o mesmo valendo para o princípio de abstinência, seu corolário metodológico. A recomendação de neutralidade, que envolve o modus operandi do psicanalista, nos aponta para a dimensão ética da psicanálise porque coloca como princípio que o psicanalista não tente conduzir o sujeito e não coloque como medida de sua ação nenhum juízo de valor sobre o que escuta ou possa vir a escutar. Por conseguinte, dirigir o tratamento sem, contudo, conduzir o sujeito, é o grande desafio ético do psicanalista. Caberia ao psicanalista, portanto, suportar frustrar as demandas do analisante, ou seja, literalmente "deixá-lo a desejar". Para Freud, abster-se de oferecer satisfações imediatas e substitutivas ao sujeito exigirá, do psicanalista, certo grau de desprendimento egóico. Portanto, essa neutralidade seria o modo ético de conduzir o tratamento "sem temor e sem piedade"; e sem a influência dos próprios ideais e de seus derivados imediatos, os pré-conceitos. 


\section{2- A leitura lacaniana}

Ao percorrermos o primeiro Seminário de Lacan (1985[1953-1954]), dedicado aos escritos técnicos de Freud, vemos aí grandes evidências do conhecido "movimento de retorno a Freud", movimento esse marcado pela releitura do texto freudiano em sua língua de origem, o alemão. Com a retomada da palavra de Freud, Lacan pretendia, naquele momento, demarcar os desvios, tanto de leitura/ interpretação da teoria, quanto da condução do tratamento psicanalítico. Contudo, nesse mesmo Seminário, além do movimento de retorno ao texto freudiano com o objetivo de marcar os desvios da prática psicanalítica, não encontramos nenhuma formulação, digna de nota, que trouxesse qualquer articulação nova acerca dos "escritos técnicos" talvez por Lacan se encontrar aí no início de seu ensino. O mesmo não se pode dizer do Seminário dedicado à ética da psicanálise (LACAN, 1988[1959-1960]), Seminário esse marcado por formulações e articulações inéditas sobre conceitos psicanalíticos diversos, principalmente os que dizem respeito à prática da psicanálise, ou seja, ao juízo que o psicanalista faz de suas palavras e de seus atos durante a condução do tratamento. De certa forma, Lacan aí postula que tudo o que diz respeito à "técnica da psicanálise" deveria ser localizado - e, por conseqüência, tratado dentro da dimensão ética, dimensão essa inferida $^{2}$ a partir do campo epistemológico inaugurado por Freud.

$\mathrm{Na}$ abertura desse Seminário, Lacan (1988[1959-1960], p. 10), ao citar uma fórmula de Hesnard, localiza a ética da psicanálise no "universo mórbido da falta". E mesmo rejeitando tal fórmula - pois embora a experiência psicanalítica possa reduzir a morbidez, ela nunca poderia "volatilizar a falta" - , Lacan (1988[1959-1960]) lembra ainda aos presentes que é com a "atração da falta" que o psicanalista lida o tempo todo na direção do tratamento. Ele estabelece aí um ponto de vista essencial à ética da psicanálise, principalmente quando o contrapõe à tradição e reflexão moralista, que via na ética somente sua face de "ideal de conduta". Daí a razão de ter tomado a ética pelo viés da falta e não dos ideais e de seu derivado lógico elementar: o desejo.

Ao se voltar para a obra freudiana, destacadas nela as origens paradoxais do desejo, Lacan (1988[1959-1960]) se pergunta onde buscar as principais referências, feitas pelo mestre de Viena, à falta enquanto fundamento do desejo.

Será a falta que a obra freudiana designa em seu início, o assassinato do pai, esse grande mito colocado por Freud na origem do desenvolvimento da cultura? Ou será a falta mais obscura e ainda mais original, cujo termo ele chega a colocar no final de sua obra, o instinto (sic) de morte, dado que o homem está ancorado, no que tem de mais profundo em si mesmo, em sua temível dialética? (LACAN, 1988[1959-1960]), p. 11).

Vê-se que o programa de Lacan para o Seminário dedicado à ética da psicanálise foi fundado, prioritariamente, nas referências freudianas ao pai primevo, à Lei, à Coisa (das Ding), ao mal-estar na civilização e à pulsão de morte. Essas referências demarcariam um campo ético propriamente freudiano, campo 
em que o desejo (em seu objeto-causa) é posto como princípio elementar examinado por Lacan, a partir da literatura libertina (Sade, Mirabeau, Diderot) e do fenômeno cultural-artístico do amor cortês.

Da dimensão tragédia da experiência psicanalítica, a partir de uma leitura singular da trajetória de Antígona, Lacan extrai uma máxima aplicável à ética do desejo: "Agiste em conformidade com seu desejo?" (LACAN, 1988[19591960], p. 373-390). Mas o que é o desejo? Ao examinar a definição freudiana de sublimação, Lacan recapitula sua própria concepção acerca do desejo.

Na definição de sublimação como satisfação sem recalque há, implícito ou explícito, passagem do não-saber ao saber, reconhecimento disto, que o desejo nada mais é que a metonímia do discurso da demanda. É a mudança como tal. Insisto - essa relação propriamente metonímica de um significante ao outro que chamamos de desejo, não é o novo objeto, nem o objeto anterior, é a própria mudança de objeto em si (LACAN, 1988[1959-1960], p. 352).

E mesmo ao articular demanda (D), desejo (d) e necessidade (N), Lacan (1998a[1958]) reafirma a característica metonímica do desejo ao relembrar sua própria formulação acerca da política do psicanalista - como e enquanto "falta-a-ser".

Ousando formular uma satisfação que não é paga com um recalque, o tema colocado no centro, promovido em sua primazia, é o que é o desejo? A propósito disto posso apenas lembrar-lhes o que nessa época articulei realizar seu desejo coloca-se sempre numa perspectiva de condição absoluta. É na medida em que a demanda está para além e para aquém de si mesma, que, ao se articular com o significante, ela demanda sempre outra coisa, que, em toda satisfação da necessidade, ela exige outra coisa, que a satisfação formulada se estende e se enquadra nessa hiância, que o desejo se forma como o que suporta essa metonímia, ou seja, o que quer dizer a demanda para além do que ela formula. E é por isso que a questão da realização do desejo se formula necessariamente numa perspectiva de Juízo final. Tentem, perguntar-se o que pode querer dizer ter realizado seu desejo se não é de tê-lo realizado, se podemos assim dizer, no final. É essa invasão da morte na vida que confere seu dinamismo a toda questão, quando ela tenta formular-se, sobre o tema da realização do desejo. Para ilustrar o que dizemos, se colocarmos a questão do desejo a partir do absolutismo parmenídico (sic), na medida em que ele anula tudo o que não é o ser, diremos nada é o que não nasceu, e tudo o que existe não vive senão na falta a ser" (LACAN, 1988[1959-1960], p. 353). 
Portanto, para Lacan (1988[1959-1960]), na raiz ética da psicanálise uma vez considerados os fundamentos freudianos é colocado o desejo como/enquanto fundado na/pela falta, paradoxalmente: no sentido de "ausência de" (hiância) e de "crime" (transgressão).

Por esse aspecto, consideramos o ensino de Lacan coerente aos princípios éticos elementares da psicanálise, principalmente quando toma o desejo como causa - em seu ser-de-falta, ser-de-objeto, portanto - que faz mover o sujeito ( $a \rightarrow$ \$) da indeterminação característica do significante (LACAN, 1967-1968).

Sobre as relações do desejo com a demanda de felicidade, sustentada na noção do "Bem Supremo" aristotélico e freqüentemente dirigida ao psicanalista, Lacan esclarece:

Eis o que convém relembrar no momento em que o analista se encontra em posição de responder a quem lhe demanda a felicidade. A questão do Bem Supremo se coloca ancestralmente para o homem, mas ele, o analista, sabe que essa questão é uma questão fechada. Não somente o que se lhe demanda, o Bem Supremo, é claro que ele não o tem, como sabe que não existe. Ter levado uma análise a seu termo nada mais é do que ter encontrado esse limite onde toda a problemática do desejo se coloca (LACAN, 1988[1959-1960], p. 359).

Sopesando a teoria estabelecida por Freud, principalmente através do conceito de "Princípio do Prazer", Lacan entende que aí se fez uma verdadeira revolução ética que ia muito além de tudo o que havia sido formulado desde Aristóteles. A concepção aristotélica da felicidade - sustentada nas virtudes do mestre antigo e no princípio do "Bem Supremo" é, por Freud e por Lacan, radicalmente contestada. É o que nos elucida esse estrato de Rabinovich:

Freud introduz um pressuposto que a Antiguidade grega como tal não tinha; não só o fato de que a satisfação seja alucinatória, que busque uma identidade de signos, que tudo o que dura demais nos aborrece - é o que marca finalmente quando disse que nos traz um leve contentamento -, senão que ademais insiste em que nada no micro ou no macrocosmo, no universo, está destinado para que o homem seja feliz, e que esse, em todo caso, é um conto que o homem se inventou. Isto implica, Freud o examina e está na base da experiência de satisfação e seu caráter alucinatório, este fato de que não há nada no cosmos que prepare a humanidade para ser feliz, é precisamente a inexistência de um Bem Soberano (sic) (RABINOVICH , 19--?, p. 3).

E será ainda para contrapor-se, cada vez mais, às éticas fundadas nesse princípio aristotélico que Freud (1969-1980[1930]) adotará a expressão “malestar" do sujeito na civilização. Já Lacan, no tom que dá ao Seminário 7, faz 
uma leitura, a mais freudiana possível, do que possa ser um "bem" para a psicanálise. Sustenta ele aí que, no âmbito particular, o Bem Supremo proibido, interditado e perdido por meio da interdição do incesto - é a mãe. E que é com a renúncia a esse "bem" elementar que o ser humano paga seu acesso ao desejo, constituindo-se como sujeito moral.

Lacan (1998a[1958]), nos lembra que o psicanalista também paga algo para ocupar sua função: com palavras, na interpretação, por tática; e com sua pessoa, na transferência, por estratégia. Entendemos ser esta a versão lacaniana para o conhecido "princípio de abstinência", estabelecido por Freud para orientar o psicanalista na condução dos tratamentos: abster-se de tentar satisfazer as demandas, sempre regressivas, vindas do sujeito, ou seja, deixar o sujeito na insatisfação imanente ao desejo insatisfação essa que tanto caracteriza o discurso histérico em sua abertura ao inconsciente, à associação livre. Abster-se disso, segundo Freud, uma vez estabelecida a transferência, colocaria o sujeito sob a perspectiva desse discurso, o histérico, porta de entrada necessária ao tratamento psicanalítico $\left(\$ \rightarrow \mathrm{S}_{1}\right)$.

Observamos que Lacan, durante todo o desenrolar do Seminário 7, subentendidamente ou não, jamais abandona a perspectiva de que é a partir dos fios do juízo feito sobre o seu agir que o psicanalista constrói sua ética, ou seja, que a ética emana do ato do psicanalista durante a condução do tratamento. É ao reinventar a ética do desejo, relançando-a a partir da condução de cada psicanálise, que o psicanalista se afirmaria em sua legítima diferença.

$\mathrm{O}$ que um analista tem a dar, contrariamente ao parceiro do amor, é o que a mais linda noiva do mundo não pode ultrapassar, ou seja, o que ele tem. E o que ele tem nada mais é que seu desejo, como o analisado, com a diferença de que é um desejo prevenido. O que pode ser um tal desejo, propriamente falando, o desejo do analista? Desde já, podemos no entanto dizer o que ele não pode ser. Ele não pode desejar o impossível (LACAN, 1988[1959-1960], p. 360).

Afirmada está, nesta formulação, uma diferença básica entre o desejo do psicanalista como efeito de uma análise e o desejo do analisado. O psicanalista está "prevenido" em seu desejo e devido ao que foi sua experiência vivida como analisante dos enganos necessários ao início do trabalho psicanalítico, principalmente do engano do "sujeito-suposto-saber" como verdadeiro pivô da transferência. E é ao referir-se ao entusiasmo lacaniano que acompanha a formação do psicanalista, caracterizada não só, mas principalmente pela destituição da transferência, que Castro (2006, p. 103) enunciou:

Por suportar o peso do semblant de objeto (agalma) e ver atribuída a ele a ficção de verdade característica dessa função (o sujeito-suposto-saber), o analista, já destituído subjetivamente das identificações aos semblants (significantes) do Outro $[\mathrm{I}(\mathrm{A})]$, não os 
defende nem os estimula, apenas os suporta, servindose deles como meio de condução da cura e não como um fim em si mesmo.

Ter estabelecido a transferência como uma das condições necessárias ao trabalho psicanalítico é algo que já se encontrava sob a pena de Freud, ${ }^{3}$ que sempre nos alertou para seu aspecto paradoxal, ou seja, a transferência como condição (meio) e como resistência (obstáculo) ao tratamento. Esse paradoxo pode ser assim formulado: "graças à transferência e apesar dela".

Ao abordá-la pelo viés da suposição de saber a um sujeito, ou seja, por seu pivô, Lacan a entende como uma formação do inconsciente a ser manejada estrategicamente pelo psicanalista durante a condução do tratamento, justo por sua íntima relação com o desejo inconsciente. Daí a sua fórmula "clínica sob transferência" para nos dizer que a transferência abre perspectiva ao sujeito do inconsciente e é por esse aspecto que ela é meio e não um fim. Todavia, a sua destituição implica no desengano ou ao menos na relativização dos poderes do "sujeito-suposto-saber".

Entretanto, se no início do tratamento, por decorrência da estratégia do psicanalista, o desejo é artificialmente localizado na transferência, no final, uma vez desvinculado/desenganado desta, ele (d), agora livre das resistências do eu, ressurge e se move de modo inédito. Conseqüentemente, "o desejo do psicanalista" (desejo prevenido) se torna um grande operador ético da psicanálise que, como tal, aponta para a importância da função do desejo em psicanálise.

Sobre a função do desejo (érós) em sua relação fundamental com a morte (thánatos), Lacan a apreende da tragédia antiga. Édipo e Antígona são aqui suas referências principais. A trajetória do herói grego, consentindo em morrer por uma causa própria, em vez de se render ao "serviço dos bens", chamou a atenção de Lacan. A posição do herói no "entre-duas-mortes" se destaca principalmente quando pomos em exame a recusa de Antígona em recuar, sem temor e sem piedade, frente a seu desejo, mesmo que ao custo do risco ou certeza de sua própria morte. Não haveria bem privado, bens de família, bens do ofício, bens da Cidade ou bens morais que a fizessem desistir de adentrar na zona/limite onde procura seu desejo. E é por se ocupar da relação à qual a psicanálise nos leva, qual seja, a relação do agir com o desejo que o habita, que Lacan (1988[1959-1960, p. 375-376) nos diz:

A ética da análise não é uma especulação que incide sobre a ordenação, a arrumação, do que chamo de serviço dos bens. Ela implica, propriamente falando, a dimensão que se expressa no que se chama de experiência trágica da vida.

Ele reconhece assim na experiência tragédia do herói antigo, notadamente em Antígona a natureza do desejo que está no âmago da experiência psicanalítica, formulando-a em uma máxima com valor de Juízo Final: “Agiste em conformidade com o desejo que te habita?" (LACAN, 1988[1959-1960], p. 376). 
Essa abordagem do desejo se opõe à ética tradicional, ética esta que, segundo Lacan, trabalha a favor da manutenção dos poderes relativos ao serviço dos bens. A ética de Aristóteles é aqui tomada como representativa da posição de fundar-se:

[...] inteiramente numa ordem certamente arrumada, ideal, mas que responde, quanto à política de seu tempo, à estrutura da Cidade. Sua moral é uma moral de mestre, feita para as virtudes do mestre, e vinculada a uma ordem dos poderes (LACAN, 1988[1959-1960], p. 377).

E, ainda: "A moral do poder, do serviço dos bens é - quanto ao desejo, vocês podem ficar esperando sentados” (LACAN, 1988[1959-1960], p. 378).

O imperativo categórico kantiano, a obrigação, o "Tu deves" incondicional, se impõe pela necessidade de uma razão prática. E Lacan entende que o lugar em que o imperativo categórico se faz presente, assim como os mandamentos da tradição judaico-cristã, é o mesmo lugar ocupado pelo desejo. "O reviramento que comporta nossa experiência situa no centro uma medida incomensurável, uma medida infinita que se chama desejo" (LACAN, 1988[1959-1960], p. 378). E mais adiante, ele precisa a relação elementar do desejo com o significante: "É na medida em que o sujeito se situa e se constitui em relação ao significante, que nele se produz essa ruptura, essa divisão, essa ambivalência em cujo nível se situa a tensão do desejo" (LACAN, 1988[1959-1960], p. 380).

Vê-se claramente que o ensino de Lacan (1988[1959-1960]) principalmente no Seminário dedicado à ética da psicanálise, foi intensamente pautado na importância e no lugar concedido ao desejo. As inúmeras formulações sobre o desejo, apresentadas nesse Seminário, se articulam e se desenvolvem a ponto de culminarem, no final, na afirmação de três proposições de cunho psicanalítico:

Articulei-lhes, portanto, três (sic) proposições. A única coisa de que se pode ser culpado é de ter cedido de seu desejo.

Em segundo lugar a definição do herói é aquele que pode impunemente ser traído.

Em terceiro lugar, isto não está absolutamente ao alcance de todo o mundo, e é a diferença entre o homem comum e o herói, mais misteriosa do que se acredita. Para o homem comum a traição, que se produz quase sempre, tem como efeito o de repeli-lo de maneira decisiva para o serviço dos bens, mas com a condição de que ele não reencontrará jamais o que o orienta verdadeiramente nesse serviço. Enfim, o campo dos bens, naturalmente que existe, não se trata de negá-los, mas, revirando a perspectiva que lhes proponho, quarta proposição - Não há outro bem senão o que pode servir para pagar o preço ao acesso ao desejo, na medida em que esse desejo, nós o definimos como metonímia de nosso 
ser. O arroio onde se situa o desejo não é apenas a modulação da cadeia significante, mas o que corre por baixo, que é, propriamente falando, o que somos, e também o que não somos, nosso ser e nosso não-ser - o que no ato é significado, passa de um significante ao outro da cadeia, sob todas as significações (LACAN, 1988[1959-1960], p. 385).

É com esse tom ético, acompanhado da formalização dessas quatro proposições ético-psicanalíticas, que Lacan dá por encerrado esse Seminário. Conclui aí que o desejo é uma via em que não se pode avançar sem nada pagar. Se paga "com uma libra de carne" (LACAN, 1988[1959-1960], p. 386), mesma expressão, puramente metonímica, utilizada em "A direção do tratamento e os princípios de seu poder" (LACAN, 1998a[1958]) para se referir ao que o sujeito em análise paga, ao que lhe custa o tratamento, custo esse correlato ao pago pelo herói trágico quando decide não ceder de seu desejo, quando decide adentrar na zona do "entre-duas-mortes".

Lacan (1998b[1966]) considerou a ciência como animada por algum desejo misterioso ou seja, como animada pelo sujeito (\$) que a faz/usa e dela goza. Isso o fez recapitular alguns dos tratamentos históricos dados ao desejo, principalmente em relação ao saber científico.

O que, em fato de ciência, ocupa atualmente o lugar do desejo, é muito simplesmente o que se chama correntemente de ciência, aquela que vocês vêem, por ora, galopar tão alegremente, e efetivar toda espécie de conquistas ditas físicas. Creio que ao longo desse período histórico, o desejo do homem, longamente apalpado, anestesiado, adormecido pelos moralistas, domesticado pelos educadores, traído pelas academias, muito simplesmente refugiou-se, recalcou-se na paixão mais sutil, e também a mais cega, como nos mostra a história de Édipo, a paixão do saber. É essa que está tendo um andamento que ainda não deu sua última palavra (LACAN, 1988[1959-1960], p. 388-389).

"O desejo refugiou-se no saber" é, portanto, uma formulação digna de nota. E é no centro do desejo, mais especificamente no objeto que o causa e que será nomeado posteriormente de "objeto mais-gozar" que Lacan localiza das Ding -a Coisa freudiana-, (LACAN, 1998b[1966]).

A originalidade do "Princípio do Prazer" freudiano estabelecido no "Projeto para uma psicologia cientifica" (FREUD, 1969-1980[1950[1895]]) e redimensionado em “Além do princípio do prazer" (FREUD, 1969-1980[1920]) - já trazia, subentendidamente, uma posição ética a ser sustentada pelo psicanalista na direção do tratamento: jamais prometer a cura ou o bem-estar e, sim, pôr o sujeito a trabalho a partir do manejo da transferência. Essa posição em nada se subordinava à idéia de qualquer forma de bem derivado do Bem Supremo, principalmente como e enquanto fundamento para a noção de felicidade. O próprio Freud - ao criticar a 
idéia de "propósito da vida", termo esse amplamente difundido e utilizado pelos sistemas religiosos - nos esclarece algo acerca dos poderes e dos limites do "Princípio do Prazer" em sua relação com a satisfação e com a felicidade.

Dificilmente incorreremos em erro ao concluirmos que a idéia de a vida possuir um propósito se forma e desmorona com o sistema religioso. Voltar-nos-emos, portanto, para uma questão menos ambiciosa, a que se refere àquilo que os próprios homens, por seu comportamento, mostram ser o propósito e a intenção de suas vidas. $\mathrm{O}$ que pedem eles da vida e o que desejam nela realizar? A resposta mal pode provocar dúvidas. Esforçam-se para obter felicidade; querem ser felizes e assim permanecer. Essa empresa apresenta dois aspectos: uma meta positiva e uma meta negativa. Por um lado, visa a uma ausência de sofrimento e de desprazer; por outro, à experiência de intensos sentimentos de prazer. Em seu sentido mais restrito, a palavra "felicidade" só se relaciona a esses últimos. Em conformidade a essa dicotomia de objetivos, a atividade do homem se desenvolve em duas direções, segundo busque realizar de modo geral ou mesmo exclusivamente um ou outro desses objetivos. Como vemos, o que decide o propósito da vida é simplesmente o programa do princípio do prazer. Esse princípio domina o funcionamento do aparelho psíquico desde o início. Não pode haver dúvida sobre sua eficácia, ainda que o seu programa se encontre em desacordo com o mundo inteiro, tanto com o macrocosmo quanto com o microcosmo. Não há possibilidade alguma de ele ser executado; todas as normas do universo são-lhe contrárias. Ficamos inclinados a dizer que a intenção de que o homem seja "feliz" não se acha incluída no plano da "Criação". O que chamamos de felicidade no sentido mais restrito provém da satisfação (de preferência, repentina) de necessidades represadas em alto grau, sendo, por sua natureza, possível apenas como uma manifestação episódica. Quando qualquer situação desejada pelo princípio do prazer se prolonga, ela produz tão-somente um sentimento de contentamento muito tênue. Somos feitos de modo a só podermos derivar prazer intenso de um contraste, e muito pouco de um determinado estado de coisas. Assim, nossas possibilidades de felicidade sempre são restringidas por nossa própria constituição. Já a infelicidade é muito menos difícil de experimentar. (FREUD, 1969-1980[1930], p. 94-95).

Situar a ética da psicanálise fora do reino do Bem Supremo aristotélico e para muito aquém dos ideais do eu - ou seja, na Coisa - foi uma importante lição que Lacan extraiu da leitura, não só do "Projeto", mas de toda a obra freudiana. 
Para tal, ele estabelece, no Seminário 7, um programa de entrada no campo da Coisa, uma topologização da Coisa, referida aí como um lugar, um lugar sempre vazio, ou seja, pleno em sua falta.

Inúmeras são então as formulações apresentadas por Lacan acerca da Coisa (das Ding). Ao propor uma releitura exegética do "Projeto" de Freud (19691980[1930]) sob o ponto de vista da ética da psicanálise, Lacan (1988[1959-1960], p. 49) acredita "que a oposição entre o princípio do prazer e o princípio da realidade, a do processo primário e do processo secundário sejam menos da ordem da psicologia do que da ordem da experiência ética".

É, portanto, no rastro da metapsicologia freudiana que Lacan (1988[19591960]), procura e encontra uma elaboração que reflete um pensamento ético. A intuição freudiana central, relativa ao "Projeto", já traz, para Lacan, uma marca ética, marca essa circunscrita principalmente no conceito de das Ding. Ele concebe o aparelho psíquico freudiano como uma topologia da subjetividade e destaca aí "a Coisa" como uma coordenada fundamentalmente ética que remete, inevitavelmente, à origem alucinatória do desejo, à "experiência de satisfação" freudiana. Lacan (1988[1959-1960]), encontra, portanto, a partir de um reexame minucioso do "Projeto", algumas coordenadas do objeto, todas elas sustentadas nessa alucinação fundamental localizada na origem do desejo humano, e que tem na Coisa o objeto ao mesmo tempo perdido e reencontrado/relançado no horizonte, desejo ao modo de causa presente.

O mundo freudiano, ou seja, o da nossa experiência, comporta que é esse objeto, das Ding, enquanto o Outro absoluto do sujeito, que se trata de reencontrar. Reencontramo-lo no máximo como saudade. Não é ele que reencontramos, mas suas coordenadas de prazer, é nesse estado de ansiar por ele e de esperá-lo que será buscada, em nome do princípio do prazer, a tensão ótima abaixo da qual não há nem percepção nem esforço. No final das contas, sem algo que o alucine enquanto sistema de referência, nenhum mundo da percepção chega a ordenar-se de maneira válida, a constituir-se de maneira humana. O mundo da percepção nos é dado por Freud como dependendo dessa alucinação fundamental sem a qual não haveria nenhuma atenção disponível (LACAN, 1988[1959-1960], p. 69).

Há, portanto, já a partir da orientação ética freudiana esboçada no "Projeto", um destaque dado à Coisa. O que Lacan (1988[1959-1960], p. 71), aí afirma é que ela:

[...] é originalmente o que chamaremos de o fora-dosignificado. É em função desse fora-do-significado e de uma relação patética a ele que o sujeito conserva sua distância e constitui-se num mundo de relação, de afeto primário, anterior a todo recalque. 
É nessa perspectiva que Lacan lançará sua fórmula sobre a sublimação: "Ela eleva um objeto à dignidade da Coisa” (LACAN, 1988[1959-1960], p. 141-142).

A Coisa envolve, portanto, um limite, uma fronteira que indica o para-além ou para-aquém do significante. No Seminário dedicado à ética da psicanálise, o que Lacan aborda em termos éticos, referindo-se para tal à Coisa, será tratado, posteriormente, principalmente no "Seminário 20: mais, ainda" (LACAN, 1982[1972-1973]), em termos de objeto, de objeto mais-gozar.

A Coisa freudiana é, então, o problema central da ética da psicanálise.

Essa Coisa, da qual todas as formas criadas são do registro da sublimação, será sempre representada por um vazio, precisamente pelo fato de ela não poder ser representada por outra coisa ou, mais exatamente, de ela não poder ser representada senão por outra coisa. Mas, em toda forma de sublimação o vazio será determinante (LACAN, 1988[1959-1960], p. 162).

Esse vazio é, pois, o que está, segundo a releitura lacaniana, no centro do conceito de sublimação. Vazio esse que a arte contorna, organizando-se em torno dele; que a religião evita, radicalmente; e que o discurso da ciência descrê (Unglauben), tanto quanto o paranóico, justamente por não porem fé na realidade psíquica.

Por isso, conclui Lacan (1988[1959-1960], p. 168):

Nem a ciência, nem a religião são aptas para salvar a Coisa, nem de nos dá-la, uma vez que o círculo encantado que dela nos separa é estabelecido por nossa relação com o significante. Como lhes disse, a Coisa é o que do real padece dessa relação fundamental, inicial, que induz o homem na via do significante, pelo fato mesmo de ele ser submetido ao que Freud chama de princípio do prazer, e que está claro, espero, no espírito de vocês, que não é outra coisa senão a dominância do significante digo, o verdadeiro princípio do prazer tal como ele funciona em Freud. Em suma, é o efeito da incidência do significante sobre o real psíquico que está em causa.

A Coisa define, então, o que é propriamente humano, ela é efeito da subordinação de sujeito ao significante. Daí Lacan (1988[1959-1960], p. 262) propor, nesse mesmo Seminário, a expressão "campo da Coisa" para designar o lugar em que:

[...] se projeta algo para-além, na origem da cadeia significante, lugar onde tudo o que é lugar do ser é posto em causa, lugar eleito onde se produz a sublimação, da qual Freud nos dá o exemplo mais maciço. 
Ainda sobre o desejo, uma vez afirmado sua fundação na Coisa, Lacan (1988[1959-1960]) nos aponta duas grandes barreiras erguidas ao seu redor: o belo, pela via da estética; e o bem, pela via da moral. Estes seriam os dois grandes obstáculos a qualquer tentativa de aproximação do sujeito dela, não sendo à toa usualmente se colocarem a serviço dos bens. Ao contrário, o discurso psicanalítico leva o sujeito para mais-além dos limites do bem e da beleza e mesmo de qualquer homeostase do aparelho psíquico.

\title{
4.0- Resultados
}

Por meio de uma leitura exegética dos chamados artigos "técnicos" de Freud foi-nos possível observar que neles não são apresentados quaisquer procedimentos, costumes ou rotinas do tratamento psicanalítico, nem tampouco normas para a prática da psicanálise ou mesmo instruções sobre como conduzir o tratamento. Mesmo a palavra "técnica" tendo sido usada por Freud, notamos que seu emprego jamais aponta na direção de um manual de bem-fazer (know-how) a psicanálise, jamais denotam o sentido de instruções a serem seguidas pelo psicanalista. E assim sendo, a expressão "técnica" mostrou-se, já desde o início da pesquisa, um tanto inadequada, na medida em que dá margem ao entendimento da prática psicanalítica como um saber-fazer possível de transmissão em forma de manual, o que é um ledo engano. Expressões como "orientações", "coordenadas" e "recomendações" parecem mais adequadas, tendo sido inclusive inúmeras vezes utilizadas por Freud.

Em alguns destes textos, Freud (1969-1980[1905, 1908, 1910a, 1910b, 1912b, 1913, 1914, 1917a, 1917b, 1919, 1926, 1933, 1937]; LOEWENFELD, 1969-1980[1904]) afirma, categoricamente, que a técnica da psicanálise não pode ser apreendida em livros, mas sim na própria análise do interessado, em sua própria experiência de analisando.

\begin{abstract}
Agora que um considerável número de pessoas está praticando a psicanálise e, reciprocamente, trocando observações, notamos que nenhum psicanalista avança além do quanto permitem seus próprios complexos e resistências internas; e, em conseqüência, requeremos que ele deva iniciar sua atividade por uma auto-análise e levá-la, de modo contínuo, cada vez mais profundamente, enquanto esteja realizando suas observações sobre seus pacientes. Qualquer um que falhe em produzir resultados numa auto-análise desse tipo deve desistir, imediatamente, de qualquer idéia de tornarse capaz de tratar pacientes pela análise (FREUD, 19691980[1910a], p. 130).
\end{abstract}

Portanto, a psicanálise (como teoria, método e ética) é fruto da experiência analítica e não de especulações (LOEWENFELD, 1969-1980[1904]). Sempre que Freud nos apresentou coordenadas relativas ao agir do psicanalista, estas são entremeadas de comentários sobre a análise do psicanalista: como ela foi iniciada, como caminhou e sobre sua conclusão. Para nos dizer sobre o que o 
analista aprendeu/desaprendeu, apreendeu/destituiu a partir sua própria análise, Lacan cunhou a expressão "desejo do psicanalista" que, como vimos, se caracteriza como "desejo prevenido", principalmente pelo que ao psicanalista custou (lhe foi retirado e lhe implicou, portanto, nas mudanças de posição subjetiva) a própria experiência como psicanalisante, enfim, até onde a psicanálise o levou. E é em consonância com o fundamento freudiano que Lacan subordina a direção do tratamento psicanalítico ao "desejo do psicanalista", localizando-a assim na dimensão ética e jamais técnica.

\section{0- DiscusSão}

Segundo Freud (1969-1980[1917a; 1910b]; LOEWENFELD, 19691980[1904]), a "tarefa" que o método psicanalítico se propõe a resolver pode ser expressa de diferentes formas, todas elas equivalentes: "tornar o inconsciente consciente"; "desfazer recalcamentos", lições relativas à primeira tópica do aparelho psíquico; e "lá onde está o isso, o sujeito deve aí advir", lição relativa à segunda tópica. Se para "tornar o inconsciente consciente", o psicanalista não pode deixar de dar informações sobre o que foi recalcado (FREUD, 1969-1980[1910b]), só deve fazê-lo, contudo, após duas condições terem sido alcançadas: o paciente deve ter alcançado ele próprio uma proximidade daquilo que recalcou, e já deve ter constituído uma transferência para com o psicanalista. A transferência é apontada, por um lado, como obstáculo/resistência à análise e, por outro, como condição indispensável e meio de acesso ao inconsciente "graças e apesar da transferência", podemos assim formular essa ambivalência que lhe é inerente.

Outra importante consideração ética observada nos artigos de Freud (19691980[1919]) é que o psicanalista não se dedica a dar orientação e conselho, devendo o papel de mentor ser evitado.

Recusamo-nos, da maneira mais enfática, a transformar um
paciente, que se coloca em nossas mãos em busca de auxilio,
em nossa propriedade privada, a decidir por ele o seu destino,
a impor-lhe os nossos próprios ideais, e com orgulho de um
criador, formá-lo à nossa própria imagem e verificar que isso
é bom. Ainda endosso essa recusa, e acho que é este o lugar
adequado para a discrição médica, que, em outros aspectos,
somos obrigados a ignorar [...] o paciente deve ser educado
para liberar e satisfazer a sua própria natureza e não para
assemelhar-se conosco (FREUD, 1969-1980[1919], p. 207).

Notamos quando do exame dos textos de Freud e de Lacan sobre a ética da psicanálise que o que Lacan formulou em termos lógicos, já se encontrava, se bem que de forma incipiente e muitas vezes mítica, no texto freudiano. Encontramos na obra de Freud várias passagens onde ele diz e dá a dizer que, na direção do tratamento, não há orientação ou condução do sujeito, que o lugar do psicanalista não é o lugar do mestre e, portanto, que ele não deve tentar guiar o sujeito na direção de qualquer ideal moral. Desse modo, Freud (1980[1917a]) possibilitou a Lacan formular a máxima de que o sujeito deve agir em conformidade com seu desejo. 
Dizemos a nós próprios que todo aquele que conseguiu educarse de modo a se conduzir de acordo com a verdade referente a si mesmo, está permanentemente protegido contra o perigo da imoralidade, conquanto seus padrões de moralidade possam diferir, em determinados aspectos, daqueles vigentes na sociedade (FREUD, 1980[1917a], p. 507).

"Educar-se e conduzir-se de acordo com a verdade referente a si mesmo" pode ser lido como "agir em conformidade com seu desejo", ou "não ceder de seu desejo", que Lacan propõe como uma inevitável revisão ética a que a psicanálise nos leva.

Freud (1969-1980[1919, 1933]) assinala ainda que a psicanálise não deve se colocar a serviço de qualquer perspectiva filosófica sobre o mundo, impondo-a ao sujeito, pois isso caracterizaria uma violência; e que "a educação", segundo uma orientação psicanalítica, não pode justificadamente se colocar a serviço de instituições, devendo ficar isenta das exigências reinantes na sociedade. A psicanálise não deve, portanto, servir a qualquer ideal ou a qualquer ideologia, pois seu "bem" diz respeito ao desejo. Vemos que a psicanálise não está no mesmo plano do que Lacan chamou de "serviço dos bens", não funciona sob o ideal do bem, sob a lógica do Bem Supremo, e não almeja uma harmonização psíquica. Neste ponto, "promover na ordenação da análise a normalização psicológica inclui o que podemos chamar de uma moralização racionalizante" (LACAN, 1988[19591960], p. 362). Acreditar que a meta ou a finalidade da análise é a normalização ou harmonização psíquica é um grande equívoco moral, pois a psicanálise não se propõe a defender quaisquer ideais morais. Como Freud (1980[1908]) enuncia em "Moral sexual civilizada e doença nervosa moderna" e em "O mal-estar na civilização" (1969-1980[1930]), o funcionamento pautado na obediência cega à moral e na ordenação dos serviços dos bens implica sacrifícios, especialmente em relação ao desejo, e é isso que a psicanálise questiona com profundidade. É possível dizer que a ética da psicanálise, lida e entrelida nos textos de Freud, se difere da chamada moral sexual "civilizada", justo por "ser impossível tomar partido da moralidade sexual convencional ou ter em alto apreço a forma pela qual a sociedade procura regulamentar na prática os problemas da vida sexual" (FREUD, 1980[1917a], p. 506). Mesmo afirmando que a moral sexual "civilizada" tem uma forte participação na etiologia de doenças nervosas, Freud não propõe nenhuma moral substituta, nenhuma forma alternativa de pansexualismo.

Uma observação interessante é apontada pelo próprio Strachey e também pôde ser notada por nós: a mudança ocorrida, ao longo dos artigos, na forma como Freud se refere aos que exercem a psicanálise. Nos primeiros artigos da série examinada, parece evidente que o analista é um médico e Freud usa aí, com freqüência, a expressão alemã Artz, que significa "médico" ou "doutor". No entanto, nos últimos artigos da série, a expressão Artz já não é mais usada de modo algum, sendo substituída por Analytiker, que significa "analista". Vemos aí uma mudança no modo de se referir ao psicanalista, certamente determinada por uma mudança de perspectiva do próprio Freud (1980[1926]), já admitindo que ele, o psicanalista, não fosse necessariamente médico. 


\section{0- Conclusão}

Nos textos examinados, bem como em toda a obra de Freud, nunca é usada a expressão "ética da psicanálise", porém, a ética psicanalítica é possível de ser inferida do método clinico (associação livre e atenção flutuante) aí proposto para o tratamento de neuróticos.

Destarte, ao retomarmos o texto freudiano, verificamos imediatamente a não pertinência, por parte do editor inglês, James Strachey, da expressão "os artigos técnicos". Observamos que o editor pretendeu, ao modo de titulação, agrupar alguns artigos freudianos pelo viés da direção do tratamento. Portanto, não foi o caso de uma tradução e, sim, de ter dado um nome ou título comum a vários artigos que tinham, no tratamento psicanalítico, seu fio condutor. Asseveramos que o exame dessa escolha de Strachey, feito à luz do texto freudiano, contribuiu decisivamente para ratificar um mal-entendido elementar gerado pelo uso dessa mesma expressão. Ao leitor desavisado ou leigo, tal expressão sugere/denota algo como um "manual de instruções", ou seja, ela estimula a leitura/entendimento de que o método clínico freudiano se reduz a uma técnica, a um manual de bem-fazer que guiará, com instruções, o psicanalista na condução do tratamento de neuróticos o que, comprovadamente, se mostrou ser uma leitura equivocada.

Além desse inconveniente, terminológico e epistemológico - talvez efeito antropocêntrico do tecnicismo inglês - apontamos outra inconsistência dessa expressão: Ela mantém oculta a dimensão ética da psicanálise. Notamos que, mesmo quando Freud, vez por outra, utiliza a palavra "técnica" para se referir ao tratamento psicanalítico, ele o faz cercado de cuidados e, algumas vezes, de recomendações que remetem o leitor/analista, inevitavelmente, ao que Lacan chamou de "o desejo do psicanalista", enfim, ao que, do início ao fim, foi a sua experiência com a psicanálise. É a partir dessa experiência, antes de tudo clínica da chegada à partida que a ética da psicanálise se constitui, principalmente a partir do que é aí transmitido (principalmente nas entrelinhas, no entre as palavras). Mesmo Freud não tendo usado/adotado o nome "ética da psicanálise", jamais deixou de apontar - não somente nos "artigos técnicos", mas ainda nos casos clínicos por ele relatados e mesmo nas entrelinhas dos "artigos metapsicológicos", - na direção de uma ética voltada para o desejo.

A ética psicanalítica, pensada a partir da experiência e da obra de seu fundador, foi construída, subterraneamente, a partir da clínica sustentada na transferência e encaminhada pelo método por ele inventado: a associação livre/atenção flutuante. Método clínico este voltado para a atitude subjetiva de "deixar dizer o que vem à mente", por parte do psicanalisante, e de tudo escutar, por parte do psicanalista. Por esse aspecto, as conclusões às quais chegamos dizem respeito às relações entre o método clínico-psicanalítico e a ética fundada no desejo. De modo que ter adentrado no campo da ética da psicanálise nos possibilitou entender e formular que Lacan lê, com a lupa da ética, o que Freud escreveu em termos clínico-metodológicos, mesmo que, vez por outra, sob a epígrafe de "técnica". 
Se a ética é o juízo construído a partir dos atos de um sujeito, o que a psicanálise teria a nos dizer sobre "o ato do psicanalista"? Em que ele se diferenciaria dos demais? Que juízo o psicanalista faria acerca de seu próprio ato? A abertura de um novo horizonte de pesquisa horizonte esse voltado para os operadores éticos da psicanálise, quais sejam, "o saber, o discurso, o desejo e o ato do psicanalista" é um desdobramento possível dos resultados e conclusão às quais chegamos, e que aqui apontamos.

\section{Notas}

${ }^{1}$ Comentário interlinear de um ou mais textos: aquilo que não está explicita ou diretamente expresso numa mensagem (escrita ou oral); o que está subentendido ou oculto, ou que é depreensível.

2 "Operação intelectual por meio da qual se afirma a verdade de uma proposição em decorrência de sua ligação com outras já reconhecidas como verdadeiras” (FERREIRA, 2004). Por esse aspecto, ter inferido que os "escritos técnicos" são, antes de tudo, éticos, nos exigiu o exercício de ler Freud entre as palavras, entre as linhas e, principalmente, entre seus textos.

3 Encontramos três textos freudianos, entre os "artigos técnicos", dedicados explicitamente, a começar do título, à transferência. Também Lacan dedicou um Seminário inteiro, o Seminário 8 (LACAN, 1992[1960-1961]), a esse conceito fundamental, além de uma sessão do Seminário 11 (LACAN, 1979[1964]).

\section{REFERÊNCIAS}

CASTRO, J. E. Conseqüencias éticas da teoria lacaniana dos discursos no ensino da psicanálise. 2006. Tese (Doutorado)-Instituto de Psicologia, Programa de Pós-Graduação em Teoria Psicanalítica - Universidade Federal do Rio de Janeiro, Rio de Janeiro, 2006.

FREUD, S. Projeto para uma Psicologia Científica (1950[1895]). In: SALOMÃO, J. (Coord.). Obras Psicológicas Completas de Sigmund Freud. Rio de Janeiro: Imago, 1969-1980. v. I, p. 395-452. Edição Standard Brasileira.

. A interpretação dos sonhos (1900). In: SALOMÃO, J. (Coord.). Obras Psicológicas Completas de Sigmund Freud. Rio de Janeiro: Imago, 1969-1980. v. IV e V. Edição Standard Brasileira.

- Sobre a Psicoterapia (1905). In: SALOMÃO, J. (Coord.). Obras Psicológicas Completas de Sigmund Freud. Rio de Janeiro: Imago, 1969-1980. v. VII, p. 263-268. Edição Standard Brasileira.

Moral sexual civilizada e doença nervosa moderna (1908). In: SALOMÃO, J. (Coord.). Obras Psicológicas Completas de Sigmund Freud. Rio de Janeiro: Imago, 1969-1980. v. IX, p. 185-208. Edição Standard Brasileira.

As perspectivas futuras da terapia psicanalítica (1910a). In: SALOMÃO, J. (Coord.). Obras Psicológicas Completas de Sigmund Freud. Rio de Janeiro: Imago, 1969-1980. v. XI, p. 125-136. Edição Standard Brasileira. 
FREUD, S. Psicanálise Silvestre (1910b). In: SALOMÃO, J. (Coord.). Obras Psicológicas Completas de Sigmund Freud. Rio de Janeiro: Imago, 1969-1980. v. XI, p. 207-216. Edição Standard Brasileira.

. O manejo da interpretação dos sonhos na psicanálise (1911). In: SAlOMÃ̃, J. (Coord.). Obras Psicológicas Completas de Sigmund Freud. Rio de Janeiro: Imago, 1969-1980. v. XII, p. 89-96. Edição Standard Brasileira.

. A dinâmica da transferência (1912a). In: SALOMÃO, J. (Coord.). Obras Psicológicas Completas de Sigmund Freud. Rio de Janeiro: Imago, 1969-1980. v. XII, p. 130-143. Edição Standard Brasileira.

. Recomendações aos médicos que exercem a psicanálise (1912b). In: SAlOMÃO, J. (Coord.). Obras Psicológicas Completas de Sigmund Freud. Rio de Janeiro: Imago, 1969-1980. v. XII, p. 146-159. Edição Standard Brasileira.

. Sobre o Início do Tratamento (1913). In: SALOMÃO, J. (Coord.). Obras Psicológicas Completas de Sigmund Freud. Rio de Janeiro: Imago, 1969-1980. v. XII, p. 139-158. Edição Standard Brasileira.

. Recordar, Repetir, Elaborar (1914). In: SALOMÃO, J. (Coord.). Obras Psicológicas Completas de Sigmund Freud. Rio de Janeiro: Imago, 1969-1980. v. XII, p. 193-207. Edição Standard Brasileira.

. Observações sobre o amor transferencial (1915). In: SALOMÃO, J. (Coord.). Obras Psicológicas Completas de Sigmund Freud. Rio de Janeiro: Imago, 1969-1980. v. XII, p. 208-221. Edição Standard Brasileira.

- Conferências Introdutórias sobre Psicanálise: Conferência XXVII - Transferência (1917a). In: SALOMÃO, J. (Coord.). Obras Psicológicas Completas de Sigmund Freud. Rio de Janeiro: Imago, 1969-1980. v. XVI, p. 503521. Edição Standard Brasileira.

- Conferências Introdutórias sobre Psicanálise: Conferência XXVIII - Terapia analítica (1917b). In: SALOMÃO, J. (Coord.). Obras Psicológicas Completas de Sigmund Freud. Rio de Janeiro: Imago, 1969-1980. v. XVI, p. 523539. Edição Standard Brasileira.

. Linhas de Avanço na Terapia Psicanalítica (1919). In: SALOMÃO, J. (Coord.). Obras Psicológicas Completas de Sigmund Freud. Rio de Janeiro: Imago, 1969-1980. v. XVII, p. 201-211. Edição Standard Brasileira.

. Além do princípio do prazer (1920). In: SALOMÃO, J. (Coord.). Obras Psicológicas Completas de Sigmund Freud. Rio de Janeiro: Imago, 1969-1980. v. XVIII, p. 17-90. Edição Standard Brasileira. 
FREUD, S. A questão da análise leiga (1926). In: SALOMÃO, J. (Coord.). Obras Psicológicas Completas de Sigmund Freud. Rio de Janeiro: Imago, 1969-1980. v. XX, p. 205-293. Edição Standard Brasileira.

. O mal estar na civilização (1930). In: SALOMÃO, J. (Coord.). Obras Psicológicas Completas de Sigmund Freud. Rio de Janeiro: Imago, 1969-1980. v. XXI, p. 81-177. Edição Standard Brasileira.

. Novas conferências introdutórias sobre psicanálise: conferência XXXIV (1933). In: SALOMÃO, J. (Coord.). Obras Psicológicas Completas de Sigmund Freud. Rio de Janeiro: Imago, 1969-1980. v. XXII, p. 179-185. Edição Standard Brasileira.

. Análise terminável e interminável (1937). In: SALOMÃO, J. (Coord.). Obras Psicológicas Completas de Sigmund Freud. Rio de Janeiro: Imago, 19691980. v. XXIII, p. 247-308. Edição Standard Brasileira.

INFERIDA. In: FERREIRA, A. B. H. Novo Dicionário Aurélio da Língua Portuguesa. Versão 5.0 rev. e atual. Curitiba: Positivo, 2004. CD-ROM.

LACAN, J. O Seminário: os escritos técnicos de Freud (1953-1954). Rio de Janeiro: J. Zahar, 1985. Livro 1.

. O Seminário: a ética da psicanálise (1959-1960). Rio de Janeiro: J. Zahar, 1988. Livro 7. 1992. Livro 8.

O Seminário: a transferência (1960-1961). Rio de Janeiro: J. Zahar, . O Seminário: os quatro conceitos fundamentais da psicanálise (1964). Rio de Janeiro: J. Zahar, 1979. Livro 11.

. O Seminário: o ato psicanalítico (1967-1968). [S.1.]: [s.n., 19--]. Livro 15.

\section{$\overline{\text { Livro } 20 .}$}

O Seminário: mais, ainda (1972-1973). Rio de Janeiro: J. Zahar, 1982.

A direção do tratamento e os princípios de seu poder (1958). In:

Escritos. Rio de Janeiro: J. Zahar, 1998a, p. 591-652.

A ciência e a verdade (1966). In: . Escritos. Rio de Janeiro: J. Zahar, 1998b. p. 869-892. 
LOEWENFELD, L. O Método Psicanalítico de Freud (1904[1903]). In: SALOMÃO, J. (Coord.). Obras Psicológicas Completas de Sigmund Freud. Rio de Janeiro: Imago, 1969-1980. v. 7, p. 254-262. Edição Standard Brasileira.

RABINOVICH, D. S. La ética del psicoanálisis y la originalidad del Principio del Pracer freudiano. Buenos Aires, [s.n., 19--?].

STRACHEY, J. Introdução (1966). In: FREUD, S., Artigos sobre técnica (19111915 [1914]). In: SALOMÃO, J. (Coord.). Obras Psicológicas Completas de Sigmund Freud. Rio de Janeiro: Imago, 1969-1980. v. XII, p. 111-115. Edição Standard Brasileira.

TÉCNICA. In: FERREIRA, A. B. H. Novo Dicionário Aurélio da Língua Portuguesa. Versão 5.0 rev. e atual. Curitiba: Positivo, 2004. CD-ROM.

Recebido em: agosto de 2008

Aceito em: dezembro de 2008 
